\title{
Oral Health Attitudes and Behavior among a Group of Turkish Dental Students
}

\author{
Ilkay Pekera \\ Meryem Toraman Alkurt ${ }^{b}$
}

\section{ABSTRACT}

Objectives: The purpose of this study was to evaluate self-reported oral health attitude and behavior among a group of Turkish dental students and to compare differences in oral health attitudes between years of study and gender.

Methods: This study included 267 (153 female, 114 male) dental students. A modified English version of Hiroshima University Dental-Behavioral Inventory (HU-DBI) which consists of twenty-eight dichotomous responses (yes-no) was used.

Results: Totally 141 preclinical 11,2 and $3^{\text {rd }}$ years of study) and 126 clinical students $\left(4\right.$ and $5^{\text {th }}$ years of study) who were mean age of 21.16 participated in the study. Statistically significant differences were found between years of study for brushing each of teeth carefully, cleaning the teeth well without using toothpaste, using a toothbrush which has hard bristles and for having had their dentist tell that they brush very well. There were statistically significant differences between females and males for using a toothbrush which has hard bristles and using tooth floss regularly. Statistically significant differences were found for brushing each of the teeth carefully and using mouth wash on regular basis between smokers and non-smokers.

Conclusions: This study confirmed that oral and dental health behavior and attitudes and also their knowledge about oral and dental health care of dental students improved with increasing level of education while oral and dental health care of female students were better than males and oral and dental health care of non-smokers were better than smokers. (Eur J Dent 2009;3:24-31)

Key words: Oral health behavior; Dental attitudes; Dental students; Turkey.

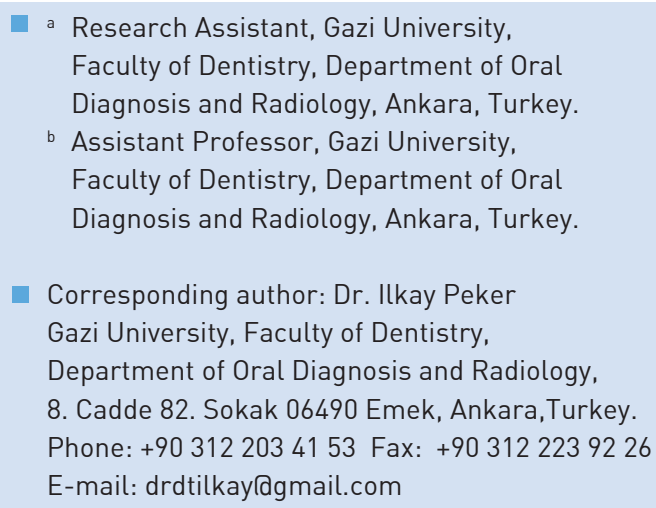

\section{INTRODUCTION}

The behavior of oral health providers and their attitudes towards their own oral health reflect their understanding of the importance of preventive dental procedures and improving the oral health of their patients. The dental students are expected to be a good example for oral health behavior. Also, dental students should instruct their friends, family members, patients and their society to maintain good oral health. ${ }^{1,2}$

The basis for health care in countries with 
similar social systems is usually the same. Comparison of countries having different bases for health care and different languages is much more complicated and time-consuming. ${ }^{3}$ Hiroshima University-Dental Behavioral Inventory (HU-DBI) was developed by Kawamura to investigate dental health behavior, attitudes and perceptions. ${ }^{4}$ Oral health attitudes and behavior of dental and/or dental hygiene students were evaluated frequently by using this scale in several countries. ${ }^{5-8}$ But there is insufficient data for oral health attitudes and behavior among Turkish dental students.

The purpose of this study was to evaluate self-reported oral health attitudes and behavior among a group of Turkish dental students by using modified HU-DBI and to compare differences in oral health attitudes between years of study and gender.

\section{MATERIALS AND METHODS}

This study included 267 dental students (153 female, 114 male) in Gazi University. Participation was voluntary and all participants remained anonymous. Demographic information was obtained including age, gender and years of study. The data collection was conducted during the autumn semester of academic year 2007-2008.

A modified English version of HU-DBI survey (Table 1) which consists of twenty-eight dichotomous responses (yes-no) was used in this study. While first 25 items of the inventory were related with oral health attitudes and behavior, last 3 items were related with smoking habit of dental students. This inventory has good test-retest reliability as well as good translated validity. ${ }^{9}$ The translation was discussed with one expert who had experience with questionnaires and survey research. Only minor corrections were made and resulting version was used in the present study. No separate validity testing was performed from the English to Turkish translation. The aim of this study was explained and the students completed the questionnaires in their classrooms during one lecture.

Data analysis

Data analysis was performed by using SPSSversion 11.5 for Windows (SPSS Inc., IL). Each item of the inventory was analyzed with Kruskal Wallis test for years of study and analyzed with
Mann Whitney U test for gender. Chi-square test was performed for analysis between each of first 25 items and last 3 items.

Table 1. A modified English version of HU-DBI survey.

Items

1 I live with family now

2 I had been to a dentist office before

3 I don't worry much about visiting the dentist

4 My gums bleed when I brush my teeth

5 I have noticed some white sticky deposites on my teeth

6 I use a child sized toothbrush

7 I think that I cannot help having false teeth when I am old

81 am bothered by the color of my gums

9 I worry about the color of my teeth

10 I think my teeth are getting worse despite my daily brushing

11 I brush my teeth twice daily or more

12 I brush each of my teeth carefully

13 I have never been taught professionally how to brush

14 I think I can clean my teeth well without using toothpaste

15 I often check my teeth in mirror after brushing

16 I worry about having bad breath

17 It is impossible to prevent gum disease with tooth brushing alone

18 I put off going to the dentist until I have toothache 19 I use a toothbrush which has hard bristles.

20 I don't feel I've brushed well unless I brush with strong strokes

21 I feel I sometimes take too much time to brush my teeth

22 I have had my dentist tell me that I brush very well 23 I do use tooth floss on regular basis

24 I do use mouth wash on regular basis

25 I am satisfied with the appearance of my teeth

26 I am a smoker

27 I smoke more than 10 cigarettes per day

28 I have been smoking for more than one year 


\section{RESULTS}

Totally 267 dental students 1153 female, 114 male) who were mean age of 21.16 and consisting 141 preclinical 11,2 and $3^{\text {rd }}$ years of study) and 126 clinical students ( 4 and $5^{\text {th }}$ years of study) participated in the study (Table 2).

Percentages and analysis of "yes" responses according to years of study is shown in Table 3 . Statistically significant differences $(P<.05)$ were found for item 1, 12, 14, 19, 22, 26 and 28 between years of study. For living with family (item 1), there were statistically significant differences $(P<.05)$ between $1^{\text {st }}-5^{\text {th }}, 2^{\text {nd }}-5^{\text {th }}$ and $3^{\text {rd }}-5^{\text {th }}$ years of study. For brushing each of teeth carefully (item 12), statistically significant differences $(P<.05)$ were found between $1^{\text {st }}-2^{\text {nd }}, 1^{\text {st }}-3^{\text {rd }}, 1^{\text {st }}-4^{\text {th }}$ and $1^{\text {st }}-5^{\text {th }}$ years of study. For cleaning the teeth well without using toothpaste (item 14), there were statistically significant differences $(P<.05)$ between $1^{\text {st }}-5^{\text {th }}$, $2^{\text {nd }}-5^{\text {th }}, 3^{\text {rd }}-5^{\text {th }}$ and $4^{\text {th }}-5^{\text {th }}$ years of study. For using a toothbrush which has hard bristles (item 19), statistically significant differences $(P<.05)$ were found between $1^{\text {st }}-5^{\text {th }}, 2^{\text {nd }}-5^{\text {th }}$ and $3^{\text {rd }}-5^{\text {th }}$ years of study. For having had their dentist tell that they brush very well (item 22), there were statistically significant differences $(P<.05)$ between $1^{\text {st }}-5^{\text {th }}, 1^{\text {st }}$ $4^{\text {th }}, 2^{\text {nd }}-5^{\text {th }}$ and $3^{\text {rd }}-5^{\text {th }}$ years of study. For smoking habit (item 26), statistically significant differences $(P<.05)$ were found between $2^{\text {nd }}-3^{\text {rd }}, 2^{\text {nd }}-4^{\text {th }}$ and $2^{\text {nd }}-5^{\text {th }}$ years of study. For smoking more than one year (item 28), there were statistically significant differences $(P<.05)$ between $1^{\text {st }}-3^{\text {rd }}, 1^{\text {st }}-4^{\text {th }}$ and $2^{\text {nd }}$ $4^{\text {th }}$ years of study.

Percentages and analysis of "yes" responses according to gender are shown in Table 4 . Statistically significant differences were found $(P<.05)$ between females and males for item 19 (I use a toothbrush which has hard bristles) and item 23 (I do use tooth floss on regular basis). Statistically significant differences $(P<.05)$ were found between females and males for item 26 (I am a smoker), item 27 (I smoke more than 10 cigarettes per day) and item 28 ( have been smoking for more than one year).

Analysis between each of first 25 items which respond "yes" and last 3 items which respond "yes and no" is shown in Table 5. There were statistically significant differences $(P<.05)$ between item 1 (living family)-item 26 (smoking), item 27 (smoking more than 10 cigarettes per dayl and item 28 (smoking more than one year). The rates of yes responses to items 26,27 and 28 were higher in the students not living with family than living with family. Statistically significant differences $(P<.05)$ were found for item 12 lbrushing each of the teeth carefully), item 17 (it is impossible to prevent gum disease with tooth brushing alonel and item 24 (I do use mouth wash on regular basis) between smokers and non-smokers.

\section{DISCUSSION}

Oral health behavior and attitudes among oral health workers and students were evaluated by using $\mathrm{HU}-\mathrm{DBI}$ survey worldwide in several studies, ${ }^{1,4,6}$ which were performed in different countries. Even, cultural differences in countries with similar or different social systems were investigated in previous studies. ${ }^{3,7,10-12}$ Due to lack of studies about oral health attitudes and behavior among Turkish dental students, this study is of prime importance in this field. Self-reported oral health attitudes and behavior among a group of Turkish dental students by using modified HU$\mathrm{DBI}$ and differences between years of study, gender and effect of smoking habits on oral health attitudes were evaluated.

Table 2. Sample description by year of study and gender.

\begin{tabular}{|c|c|c|c|c|c|c|c|}
\hline \multirow{2}{*}{ Years of study } & \multirow{2}{*}{$N$} & \multirow{2}{*}{$\%$} & \multirow{2}{*}{ Mean age $\pm S D$} & \multicolumn{2}{|c|}{ Female } & \multicolumn{2}{|c|}{ Male } \\
\hline & & & & $\mathrm{N}$ & $\%$ & $\mathrm{~N}$ & $\%$ \\
\hline $1^{\text {st }}$ year & 37 & 13.9 & $18.7 \pm 0.73$ & 24 & 64.9 & 13 & 35.1 \\
\hline $2^{\text {nd }}$ year & 54 & 20.2 & $20.4 \pm 0.96$ & 28 & 51.9 & 26 & 48.1 \\
\hline $3^{\text {rd }}$ year & 50 & 18.7 & $21.1 \pm 0.65$ & 28 & 56.0 & 22 & 44.0 \\
\hline $4^{\text {th }}$ year & 64 & 24.0 & $22.3 \pm 1.08$ & 40 & 62.5 & 24 & 37.5 \\
\hline $5^{\text {th }}$ year & 62 & 23.2 & $23.1 \pm 0.84$ & 33 & 53.2 & 29 & 46.8 \\
\hline Total & 267 & 100.0 & $21.4 \pm 1.69$ & 153 & 57.3 & 114 & 42.7 \\
\hline
\end{tabular}


It was reported that education about dental students is at a lower level than in industrialized health care in the pre-university curriculum could countries. They reported that $68 \%$ of the students be an important factor that can influence the oral brushed their teeth two or more times per day health attitudes of students entering dental field. ${ }^{2}$ and few subjects $(3 \%)$ used dental floss daily. Kirtiloglu and Yavuz ${ }^{13}$ indicated that self-preventive Thirty percent of the students visited a dentist for oral behavior of the Turkish non-dental university preventive treatment at least once a year. The rate Table 3. Percentages and analysis of "yes" responses according to years of study.

\begin{tabular}{|c|c|c|c|c|c|c|c|}
\hline \multirow[b]{2}{*}{ Items } & \multicolumn{5}{|c|}{ Years of study } & \multirow[b]{2}{*}{$\begin{array}{l}\text { Total } \\
\mathrm{N}(\%)\end{array}$} & \multirow[b]{2}{*}{$P$ value } \\
\hline & $\begin{array}{c}1^{\text {st }} \text { year } \\
\mathrm{N}(\%)\end{array}$ & $\begin{array}{c}2^{\text {nd }} \text { year } \\
N(\%)\end{array}$ & $\begin{array}{c}3^{\text {rd }} \text { year } \\
N(\%)\end{array}$ & $\begin{array}{c}4^{\text {th }} \text { year } \\
N(\%)\end{array}$ & $\begin{array}{c}5^{\text {th }} \text { year } \\
\mathrm{N}(\%)\end{array}$ & & \\
\hline Item 1 & $13(34.2)^{\pi}$ & $22(40.7)^{\pi}$ & $15(30.0)^{\pi}$ & 29 (45.3) & 39 (60.9) & 118 (43.7) & 0.010 \\
\hline Item 2 & 30 (78.9) & $50(92.6)$ & $38(76.0)$ & $54(84.4)$ & $58(90.6)$ & $230(90.6)$ & 0.078 \\
\hline Item 3 & $27(71.1)$ & $43(79.6)$ & $34(68.0)$ & $49(76.6)$ & 55 (85.9) & 208 (77.0) & 0.188 \\
\hline Item 4 & 8 (21.1) & 13 (24.1) & 9 (18.0) & $4(6.3)$ & 7 (10.9) & $41(15.2)$ & 0.050 \\
\hline Item 5 & $14(36.8)$ & 33 (61.1) & 32 (64.0) & $38(59.4)$ & 39 (61.9) & $156(58.0)$ & 0.079 \\
\hline Item 6 & $6(15.8)$ & 10 (18.5) & $7(14.0)$ & $5(7.8)$ & $4(6.3)$ & 32 (11.9) & 0.199 \\
\hline Item 7 & 26 (70.3) & $42(77.8)$ & $34(68.0)$ & 46 (71.9) & $54(84.4)$ & 202 (75.1) & 0.256 \\
\hline Item 8 & $4(10.8)$ & $6(11.1)$ & 10 (20.0) & $10(15.6)$ & 7 (10.9) & 37 (13.8) & 0.583 \\
\hline Item 9 & 14 (37.8) & $21(38.9)$ & $20(40.0)$ & $22(34.4)$ & 12 (19.0) & 89 (33.2) & 0.095 \\
\hline Item 10 & $6(16.2)$ & 12 (22.2) & 7 (14.0) & $9(14.1)$ & $9(14.1)$ & $43(16.0)$ & 0.724 \\
\hline Item 11 & 22 (57.9) & $41(75.9)$ & 35 (70.0) & 51 (79.7) & 51 (79.7) & $200(74.1)$ & 0.099 \\
\hline Item 12 & $11(28.9)$ & $31(57.4)^{+}$ & $31(62.0)^{+}$ & $46(71.9)^{+}$ & $36(56.3)^{+}$ & 155 (57.4) & $<0.001$ \\
\hline Item 13 & $11(29.7)$ & $21(38.9)$ & 12 (24.0) & $16(25.0)$ & 12 (18.8) & 72 (26.8) & 0.158 \\
\hline Item 14 & $12(32.4)^{\pi}$ & 22 (40.7) & 19 (38.0)ก & $27(42.2)^{\Uparrow}$ & $42(65.6)$ & 122 (45.4) & 0.005 \\
\hline Item 15 & 26 (70.3) & 44 (81.5) & 37 (74.0) & 56 (87.5) & $49(76.6)$ & 212 (78.8) & 0.229 \\
\hline Item 16 & $21(56.8)$ & $30(55.6)$ & $29(58.0)$ & $34(53.1)$ & $48(75.0)$ & 162 (60.2) & 0.093 \\
\hline Item 17 & $25(67.6)$ & 45 (83.3) & 35 (70.0) & $42(65.6)$ & 39 (60.9) & $186(69.1)$ & 0.110 \\
\hline Item 18 & $25(67.6)$ & 24 (44.4) & 21 (42.0) & 29 (45.3) & $26(40.6)$ & 125 (46.5) & 0.091 \\
\hline Item 19 & $13(35.1)$ §.ๆ & $12(22.2)^{\pi}$ & $11(22.0)^{\pi}$ & $11(17.2)$ & $5(7.8)$ & 52 (19.3) & 0.017 \\
\hline Item 20 & 8 (21.6) & 18 (33.3) & 12 (24.0) & $9(14.1)$ & $9(14.1)$ & $56(20.8)$ & 0.061 \\
\hline Item 21 & 7 (18.9) & 20 (37.0) & 20 (40.0) & $15(23.4)$ & 14 (21.9) & 76 (28.3) & 0.059 \\
\hline Item 22 & $7(18.9)^{\S . \rrbracket ~}$ & $18(33.3)^{\pi}$ & $16(32.0)^{\pi}$ & $30(46.9)$ & $33(51.6)$ & 104 (38.7) & 0.007 \\
\hline Item 23 & $8(21.6)^{\ddagger . \S}$ & $8(14.8)^{\ddagger . \S}$ & $26(52.0)$ & 27 (42.2) & $18(28.1)^{\ddagger}$ & 87 (32.3) & $<0.001$ \\
\hline Item 24 & $6(15.8)$ & 7 (13.0) & 11 (22.0) & 7 (10.9) & $6(9.4)$ & 37 (13.7) & 0.342 \\
\hline Item 25 & $20(54.1)$ & $30(55.6)$ & 29 (58.0) & 45 (70.3) & 48 (75.0) & 172 (63.9) & 0.075 \\
\hline Item 26 & $6(15.8)$ & 5 (9.3) & $16(32.0)^{s}$ & $18(28.1)^{s}$ & $15(23.4)^{\mathrm{s}}$ & 60 (22.0) & 0.036 \\
\hline Item 27 & $4(10.8)$ & $3(5.6)$ & 13 (26.0) & 12 (18.8) & $10(15.6)$ & $42(15.6)$ & 0.053 \\
\hline Item 28 & $3(8.1)^{\ddagger . \S}$ & $6(11.1) \neq$ & $15(30.0)$ & $16(25.0)$ & 12 (18.8) & 52 (19.3) & 0.036 \\
\hline
\end{tabular}

+ Difference is statistically significant with $1^{\text {st }}$ year of study $(P<.05)$.

$\int$ Difference is statistically significant with $2^{\text {nd }}$ year of study $(P<.05)$.

$\ddagger$ Difference is statistically significant with $3^{\text {rd }}$ year of study $(P<.05)$.

$\S$ Difference is statistically significant with $4^{\text {th }}$ year of study $(P<.05)$.

If Difference is statistically significant with $5^{\text {th }}$ year of study $(P<.05)$. 
of tooth brushing twice daily or more was $74.1 \%$ and the rate of usage dental floss regularly was $32.3 \%$ and $46.5 \%$ of the study sample put off going to the dentist until they have toothache among a group of Turkish dental students. The similar finding in this study may have been compared. This result exhibited that more dental health care education is effective and needed to improve oral health in Turkey.
Several studies ${ }^{1-3,8}$ reported as dental health attitudes become more positive and improved with increasing level of education. The improvement of personal oral health among dental students has shown to be linked to their dental education experience ${ }^{5}$ and oral health attitudes and behavior seem to increase significantly in the fourth and fifth years of dental education. ${ }^{6}$ In this study, statistically significant differences $(P<.05)$ were

Table 4. Percentages and analysis of "yes" responses according to gender.

\begin{tabular}{|c|c|c|c|c|}
\hline \multicolumn{5}{|c|}{ Gender } \\
\hline Items & $\begin{array}{c}\text { Female } \\
\mathrm{N}(\%)\end{array}$ & $\begin{array}{l}\text { Male } \\
\text { N (\%) }\end{array}$ & $\begin{array}{l}\text { Total } \\
\mathrm{N}(\%)\end{array}$ & $P$ value \\
\hline Item 1 & 75 (48.1) & 43 (37.7) & 118 (43.7) & 0.090 \\
\hline Item 2 & $136(87.2)$ & 94 (82.5) & $230(90.6)$ & 0.281 \\
\hline Item 3 & 115 (73.7) & 93 (81.6) & 208 (77.0) & 0.129 \\
\hline Item 4 & 25 (16.0) & $16(14.0)$ & $41(15.2)$ & 0.653 \\
\hline Item 5 & $87(56.1)$ & 69 (60.5) & $156(58.0)$ & 0.470 \\
\hline Item 6 & $16(10.3)$ & $16(14.0)$ & 32 (11.9) & 0.343 \\
\hline Item 7 & 115 (74.2) & 87 (76.3) & $202(75.1)$ & 0.691 \\
\hline Item 8 & $25(16.1)$ & 12 (10.5) & 37 (13.8) & 0.187 \\
\hline Item 9 & 58 (37.7) & 31 (27.2) & 89 (33.2) & 0.072 \\
\hline Item 10 & 23 (14.8) & 20 (17.5) & $43(16.0)$ & 0.550 \\
\hline Item 11 & 122 (78.2) & 78 (68.4) & 200 (74.1) & 0.070 \\
\hline Item 12 & $92(59.0)$ & 63 (55.3) & 155 (57.4) & 0.542 \\
\hline Item 13 & $44(28.4)$ & $28(24.6)$ & 72 (26.8) & 0.484 \\
\hline Item 14 & $63(40.6)$ & 59 (51.8) & $122(45.4)$ & 0.071 \\
\hline Item 15 & 127 (81.9) & $85(74.6)$ & 212 (78.8) & 0.144 \\
\hline Item 16 & 96 (61.9) & 66 (57.9) & $162(60.2)$ & 0.503 \\
\hline Item 17 & 113 (72.9) & 73 (64.0) & $186(69.1)$ & 0.120 \\
\hline Item 18 & 78 (50.3) & 47 (41.2) & 125 (46.5) & 0.139 \\
\hline Item 19 & 22 (14.2) & 30 (26.3) & 52 (19.3) & $0.013^{*}$ \\
\hline Item 20 & $28(18.1)$ & $28(24.6)$ & $56(20.8)$ & 0.195 \\
\hline Item 21 & 46 (29.7) & 30 (26.3) & 76 (28.3) & 0.545 \\
\hline Item 22 & 65 (41.9) & 39 (34.2) & 104 (38.7) & 0.199 \\
\hline Item 23 & 58 (37.4) & $29(25.4)$ & 87 (32.3) & $0.038^{*}$ \\
\hline Item 24 & 19 (12.2) & 18 (15.8) & 37 (13.7) & 0.394 \\
\hline Item 25 & 98 (63.2) & 74 (64.9) & 172 (63.9) & 0.776 \\
\hline Item 26 & $22(14.1)$ & 38 (33.3) & $60(22.0)$ & $<0.001 *$ \\
\hline Item 27 & 13 (8.4) & 29 (25.4) & 42 (15.6) & $<0.001 *$ \\
\hline Item 28 & $18(11.6)$ & 34 (29.8) & 52 (19.3) & $<0.001 *$ \\
\hline
\end{tabular}

* Difference is statistically significant $\mathrm{P}<.05$ 
found between first and all senior years of study for brushing each of teeth carefully and cleaning the teeth well without using toothpaste. There were statistically significant differences between preclinical and clinical students for using a toothbrush which has hard bristles and having had their dentist tell that they brush very well. The results of this study confirmed that oral and dental health behavior and attitudes and also their knowledge about oral and dental health care of dental students improved with increasing level of education in accordance with previous studies. Additionally, it was seen that responds of the students in the fourth and fifth years were mostly very similar as described by Polychronopoulou et al. ${ }^{6}$

In general, female dental students had better oral health attitudes and take better care of their

Table 5. Analysis between each of first 25 items which respond "yes" and last three items which respond "yes and no".

\begin{tabular}{|c|c|c|c|c|c|c|c|c|c|}
\hline \multirow[b]{2}{*}{ Items } & \multicolumn{3}{|c|}{ Item 26} & \multicolumn{3}{|c|}{ Item 27} & \multicolumn{3}{|c|}{ Item 28} \\
\hline & $\begin{array}{c}\text { No } \\
(N=207) \\
N(\%)\end{array}$ & $\begin{array}{c}\text { Yes } \\
(N=60) \\
N(\%) \\
\end{array}$ & $\begin{array}{c}P \\
\text { value }\end{array}$ & $\begin{array}{c}\text { No } \\
(\mathrm{N}=225) \\
N(\%)\end{array}$ & $\begin{array}{c}\text { Yes } \\
(\mathrm{N}=42) \\
\mathrm{N}(\%) \\
\end{array}$ & $P$ value & $\begin{array}{c}\text { No } \\
(\mathrm{N}=215) \\
N(\%)\end{array}$ & $\begin{array}{c}\text { Yes } \\
(N=52) \\
N(\%) \\
\end{array}$ & $P$ value \\
\hline Item 1 & $101(48.1)$ & 17 (28.3) & $0.006 *$ & 109 (48.0) & 9 (21.4) & $<0.001 *$ & 105 (48.4) & 13 (25.0) & $0.002^{*}$ \\
\hline Item 2 & 180 (85.7) & 50 (83.3) & 0.647 & 196 (86.3) & $33(78.6)$ & 0.193 & 187 (86.2) & $42(80.8)$ & 0.325 \\
\hline Item 3 & $161(76.7)$ & 47 (78.3) & 0.787 & 175 (77.1) & 32 (76.2) & 0.899 & 167 (77.0) & $40(76.9)$ & 0.996 \\
\hline Item 4 & 34 (16.2) & 7 (11.7) & 0.389 & 37 (16.3) & $4(9.5)$ & 0.262 & $36(16.6)$ & $5(9.6)$ & 0.209 \\
\hline Item 5 & $120(57.1)$ & $36(61.0)$ & 0.594 & 130 (57.5) & 26 (61.9) & 0.597 & $122(56.2)$ & 34 (66.7) & 0.174 \\
\hline Item 6 & $24(11.4)$ & 8 (13.3) & 0.687 & 25 (11.0) & $6(14.3)$ & 0.598 & 25 (11.5) & $6(11.5)$ & 0.997 \\
\hline Item 7 & 154 (73.3) & 48 (81.4) & 0.208 & $167(73.6)$ & 35 (83.3) & 0.179 & 159 (73.3) & 43 (82.7) & 0.158 \\
\hline Item 8 & 29 (13.8) & $8(13.6)$ & 0.961 & 31 (13.7) & $6(14.3)$ & 0.913 & 28 (12.9) & 9 (17.3) & 0.408 \\
\hline Item 9 & 68 (32.4) & $21(36.2)$ & 0.584 & $74(32.6)$ & $15(36.6)$ & 0.618 & 72 (33.2) & 17 (33.3) & 0.983 \\
\hline Item 10 & 34 (16.2) & $9(15.3)$ & 0.862 & 36 (15.9) & $7(16.7)$ & 0.896 & 33 (15.2) & 10 (19.2) & 0.477 \\
\hline Item 11 & $159(75.7)$ & 41 (68.3) & 0.250 & $170(74.9)$ & $29(69.0)$ & 0.428 & $163(75.1)$ & 36 (69.2) & 0.385 \\
\hline Item 12 & $127(60.5)$ & $28(46.7)$ & 0.056 & $138(60.8)$ & $17(40.5)$ & $0.014^{*}$ & 134 (61.8) & $21(40.4)$ & $0.005^{*}$ \\
\hline Item 13 & $59(28.1)$ & $13(22.0)$ & 0.353 & 62 (27.3) & 10 (23.8) & 0.638 & $58(26.7)$ & $14(26.9)$ & 0.977 \\
\hline Item 14 & $99(47.1)$ & 23 (39.0) & 0.266 & 102 (44.9) & $20(47.6)$ & 0.748 & 104 (47.9) & $18(34.6)$ & 0.083 \\
\hline Item 15 & 167 (79.5) & 45 (76.3) & 0.589 & 180 (79.3) & 32 (76.2) & 0.651 & 170 (78.3) & 42 (80.8) & 0.700 \\
\hline Item 16 & 127 (60.5) & 35 (59.3) & 0.873 & $137(60.4)$ & 25 (59.5) & 0.920 & 133 (61.3) & $29(55.8)$ & 0.465 \\
\hline Item 17 & $152(72.4)$ & $34(57.6)$ & $0.030 *$ & 165 (72.9) & $21(50.0)$ & $0.003^{*}$ & 162 (74.7) & 24 (46.2) & $<0.001 *$ \\
\hline Item 18 & 113 (53.8) & 31 (52.5) & 0.863 & 122 (53.7) & $22(52.4)$ & 0.871 & 115 (53.0) & $29(55.8)$ & 0.719 \\
\hline Item 19 & $39(18.6)$ & 13 (22.0) & 0.552 & 42 (18.5) & 10 (23.8) & 0.424 & $40(18.4)$ & $12(23.1)$ & 0.446 \\
\hline Item 20 & 43 (20.5) & 13 (22.0) & 0.795 & 47 (20.7) & 9 (21.4) & 0.915 & 44 (20.3) & $12(23.1)$ & 0.704 \\
\hline Item 21 & $60(28.6)$ & $16(27.1)$ & 0.827 & $66(29.1)$ & 10 (23.8) & 0.486 & 64 (29.5) & $12(23.1)$ & 0.356 \\
\hline Item 22 & $87(41.4)$ & $17(28.8)$ & 0.079 & 93 (41.0) & $11(26.2)$ & 0.071 & 90 (41.5) & $14(26.9)$ & 0.053 \\
\hline Item 23 & 67 (31.9) & 20 (33.9) & 0.772 & 73 (32.2) & 14 (33.3) & 0.881 & 69 (31.8) & $18(34.6)$ & 0.696 \\
\hline Item 24 & $26(12.4)$ & 11 (18.3) & 0.237 & 26 (11.5) & $11(26.2)$ & $0.011^{*}$ & 29 (13.4) & $8(15.4)$ & 0.704 \\
\hline Item 25 & 135 (64.3) & $37(62.7)$ & 0.824 & 148 (65.2) & $24(57.1)$ & 0.318 & 136 (62.7) & 36 (69.2) & 0.376 \\
\hline
\end{tabular}

* Difference is statistically significant $\mathrm{P}<.05$. 
teeth than male dental students. ${ }^{14,15}$ This condition may be explained on the basis that females usually care more about their body and appearance. They would thus be more concerned about visiting the dentist and would tend to be more educated about their dentition even before entering a course related to dentistry. ${ }^{2}$ In this study, there were statistically significant differences between females and males for only item 19 (I use a toothbrush which has hard bristles) and 23 (I do use tooth floss on regular basis). But, dental care behavior of female students such as tooth brushing twice daily or more, brushing each of the teeth carefully and usage the tooth floss regularly were better than males in this study in agreement with previous studies. ${ }^{2,14,15}$

Clinical studies ${ }^{16,17}$ and regional health surveys have found an association between smoking and poor oral health. Millar and Locker ${ }^{17}$ reported that smokers were less likely to have visited dentist regularly. The rate of smoking among Turkish university students was found to be $49.4 \% .{ }^{18}$ In this study, it was lower $(22.0 \%)$ than the prevalence of smoking among the other university students. Health care providers play an important role in educating patients about the health risks of tobacco use and in promoting tobacco cessation. ${ }^{19}$ Smoking and its association with periodontitis and many other oral diseases should be clearly taught to students as they could be role models for their future patients. ${ }^{20}$ In this study, statistically significant difference was found between brushing each of the teeth carefully and smoking. Nonsmokers were more careful about tooth brushing. Statistically significant difference was found between using mouth wash on regular basis and smoking. Usage of mouth wash regularly was more common in smokers than non-smokers. It may be related with worries about having bad breath.

\section{CONCLUSIONS}

Oral and dental health behavior and attitudes and also their knowledge about oral and dental health care of a group of Turkish dental students improved with increasing level of education. While, oral and dental health care of female students were better than males and oral and dental health care of non-smokers were better than smokers in agreement with previous studies which were performed in different countries. As a health care provider dental students should be a good model to their family members, friends and especially patients for oral health behavior. Further studies are needed to examine cultural differences between Turkish and other dental students in different countries.

\section{REFERENCES}

1. Nusair KB, Alomari Q, Said K. Dental health attitudes and behaviour among dental students in Jordan. Community Dent Health 2006;23:147-151.

2. Al-Wahadni AM, Al-Omiri MK, Kawamura M. Differences in self-reported oral health behavior between dental students and dental technology/dental hygiene students in Jordan. $J$ Oral Sci 2004;46:191-197.

3. Kawamura M, Spadafora A, Kim KJ, Komabayashi T. Comparison of United States and Korean dental hygiene students using Hiroshima University-Dental Behavioural Inventory (HU-DBI). Int Dent J 2002;52:156-162.

4. Kawamura M. Dental behavioral science-The relationship between perceptions of oral health and oral status in adults. (In Japanese). J Hiroshima Univ Dent Soc 1988;20:273-286.

5. Cortes FJ, Nevot C, Ramon JM, Cuenca E. The evolution of dental health in dental students at the University of Barcelona. J Dent Educ 2002;66:1203-1208.

6. Polychronopoulou A, Kawamura M, Athanasouli T. Oral self-care behavior among dental school students in Greece. J Oral Sci 2002;44:73-78.

7. Kawamura M, Honkala E, Widström E, Komabayashi T. Cross-cultural differences of self-reported oral health behavior in Japanese and Finnish dental students. Int Dent $J$ 2000;50:46-50.

8. Kawamura M, Iwamoto Y, Wright FA. A comparison of selfreported dental health attitudes and behavior between selected Japanese and Australian students. J Dent Educ 1997;61:354-360.

9. Kawamura M, Kawabata K, Sasahara H, Fukuda S, Iwamoto Y. Dental behavioral science Part IX. Bilinguals' responses to the dental behavioral Inventory (HU-DBI) written in English and in Japanese. J Hiroshima Univ Dent Soc 1992;22:185-199.

10. Kawamura M, Yip H-K, Hu D-Y, Komabayashi T. A crosscultural comparison of dental health attitudes and behavior among freshman dental students in Japan, Hong-Kong and West China. Int Dent J 2001;51:159-163.

11. Polychronopoulou A, Kawamura M. Oral self-care behavior: comparing Greek and Japanese dental students. Eur J Dent Educ 2005;9:164-170. 
12. Kawamura M, Wright FA, Declerck D, Freire MC, Hu D-Y, Honkala $E$, et al. An exploratory study on cultural variations in oral health attitudes, behavior and values of freshman (first-year) dental students. Int Dent J 2005;55:205-211.

13. Kirtiloglu T, Yavuz US. An assessment of oral self-care in the student population of a Turkish university. Public Health 2006;120:953-957.

14. Ostberg AL, Halling A, Lindblad U. Gender differences in knowledge, attitude, behavior and perceived oral health among adolescents. Acta Odontol Scand 1999;57:231-236.

15. Al-Omari QD, Hamasha AA. Gender-specific oral health attitudes and behavior among dental students in Jordan. $J$ Contemp Dent Pract 2005;6:107-114.

16. Brodeur JM, Payette M, Beniger M, Charbonneau A, Olivier M, Chabot D. Periodontal diseases among Quebec adults aged 35 to 44 years. J Can Dent Assoc 2001;67:34.

17. Millar WJ, Locker D. Smoking and oral health status. J Can Dent Assoc 2007;3:155.

18. Oksuz E, Mutlu ET, Malhan S. Characteristics of daily and occasional smoking among youths. Public Health 2007;121:349-356.

19. Mecklenburg RE. Tobacco prevention and control in dental practice: the future. J Dent Educ 2001;65:375-384.

20. Rivera-Hidalgo F. Smoking and periodontal disease. Periodontol 2000 2003;32:50-58. 